\title{
The European Society for Blood and Marrow Transplantation (EBMT) consensus recommendations for donor selection in haploidentical hematopoietic cell transplantation
}

\author{
Stefan O. Ciurea ${ }^{1}$ et al.
}

Received: 3 December 2018 / Revised: 25 January 2019 / Accepted: 20 February 2019 / Published online: 4 March 2019

(C) Springer Nature Limited 2019

\begin{abstract}
The number of HLA-haploidentical hematopoietic cell transplants continues to increase worldwide due to recent improvements in outcomes, allowing more patients with hematological malignancies and non-malignant disorders to benefit from this procedure and have a chance to cure their disease. Despite these encouraging results, questions remain as multiple donors are usually available for transplantation, and choosing the best HLA-haploidentical donor for transplantation remains a challenge. Several approaches to haploidentical transplantation have been developed over time and, based on the graft received, can be grouped as follows: T-cell depleted haploidentical transplants, either complete or partial, or with T-cell replete grafts, performed with post-transplant cyclophosphamide-based graft-versus-host disease (GVHD) prophylaxis, or G-CSF-primed bone marrow graft and enhanced GVHD prophylaxis. Carefully selecting the donor can help optimize transplant outcomes for recipients of haploidentical donor transplants. Variables usually considered in the donor selection include presence of donor-specific antibodies in the recipient, donor age, donor/recipient gender and $\mathrm{ABO}$ combinations, and immunogenic variables, such as natural killer cell alloreactivity or KIR haplotype. Here we provide a comprehensive review of available evidence for selecting haploidentical donors for transplantation, and summarize the recommendations from the European Society for Blood and Marrow Transplantation (EBMT) on donor selection for different transplant platforms.
\end{abstract}

\section{Introduction}

HLA-haploidentical donors are now largely employed for allogeneic hematopoietic cell transplantation (AHCT) for those patients who lack of an HLA-matched donor or need an urgent allograft. The field of haploidentical hematopoietic cell transplantation (HHCT) has grown significantly over the past decade [1, 2]. According to the 2015 European Society for Blood and Marrow Transplant (EBMT) activity survey report, the use of haploidentical donors has dramatically surged by almost $300 \%$ since the year 2005 [2]. This significant growth is primarily the result of the successful development of several novel methods to overcome the alloreactivity generated by major donor-recipient human leukocyte antigen (HLA)-disparity, and improvements in prevention and treatment of post-transplant

Stefan O. Ciurea

sciurea@mdanderson.org

Extended author information available on the last page of the article. complications, such as primary graft failure, delayed immunologic recovery or graft-versus-host disease (GVHD). Several platforms have been developed over time using either a T-cell depleted (TCD) graft (complete or partial elimination of donor $\mathrm{T}$ lymphocytes) [3-6], or T-cell replete (TCR) graft and effective GVHD prevention [using post-transplantation cyclophosphamide (PTCy) or G-CSFprimed bone marrow graft and enhanced GVHD prophylaxis] [7, 8]. Following these advances, recent results from multiple studies have shown that HHCT can provide longterm survival benefit equivalent to that of HLA-matched donor transplantation [7, 9-19]. Haploidentical donors can be identified for nearly all patients who require a transplant [20]. Based on data from the Johns Hopkins, at least 1 HLA-haploidentical first-degree relative can be identified in more than $95 \%$ of patients, and the average number of haploidentical donors per patient is two or more. In addition, second degree related donors with a full haplotype match with the recipient, have been successfully used for transplantation [20]. Consequently, with more than one haploidentical donor usually available for transplantation, a 
crucial question is which donor can lead to the best transplant outcomes.

In this review, a panel of members of the European Society for Blood and Marrow Transplantation (EBMT) and affiliates provide a comprehensive analysis of available data regarding outcomes of haploidentical transplants based on different donor characteristics and summarize recommendations regarding selection of best HLAhaploidentical donors for different haploidentical transplant platforms.

\section{Haploidentical donor transplant platforms}

To date, several methods have been developed and successfully used to control bi-directional alloreactivity from a major HLA-disparity between the donor and the recipient in HHCT, such as multiple approaches using ex vivo T-cell depletion [3-6, 21-23], either complete or partial, with or without T cell addback, as well as TCR (unmanipulated) haploidentical transplants with post-transplant high-dose cyclophosphamide [9, 24, 25], or G-CSF/antithymocyte globulin (ATG)-based GVHD prevention $[7,8,15-17,26-28]$.

\section{T cell depleted haploidentical transplantation}

T-cell depletion has been used to minimize morbidity and mortality associated with GVHD. Unfortunately, the complete removal of $\mathrm{T}$ cells from the graft has been shown to be associated with an increased risk of graft failure, delay in immunologic reconstitution post-transplant, and, in most studies, disease relapse [3, 23, 29-32]. Consequently, several novel graft manipulation techniques have been developed to compensate for these limitations and improve immune reconstitution and graftversus-tumor (GVT) effect, while limiting the development of GVHD.

\section{Ex vivo $\mathrm{T}$ cell depleted haploidentical transplant with $\mathrm{T}$ cell addback}

To facilitate engraftment and immune reconstitution T-cell addback has been used by several groups. Infusion of conventional $\mathrm{T}$ cells along with regulatory cells (Tregs) [4] or of donor T cells genetically modified with a suicide gene has been shown to partially compensate for the limitations associated with complete T-cell depletion [21, 33, 34]. Infusion of sufficient donor $\mathrm{T}$ cells may contribute to antiviral and anti-tumor responses, while GVHD was prevented by either Tregs [4] or photodepletion of alloreactive $\mathrm{T}$ cells [6] or regulated by activation of a suicide gene included in engineered donor lymphocytes [35].

\section{Selective alpha-beta T cells depletion}

The $\alpha \beta$ T-cell receptor-positive $\mathrm{T}$ cells has been recognized as the $\mathrm{T}$ cell subset mainly responsible for the occurrence of GVHD [36], while innate-like $\gamma \delta \mathrm{T}$ cells may provide an important contribution to control opportunistic infections and to exert an anti-tumor effect, without inducing GVHD. Therefore, selective depletion of $\alpha \beta$ T-cell receptor-positive T cells, in combination with removal of $\mathrm{CD} 19+\mathrm{B}$ cells from the graft for reducing the incidence of EBV-related post-transplant lymphoproliferative disorders (EBV-PTLD) was found to prevent GVHD. This method, primarily used in pediatric population, spares $\gamma \delta \mathrm{T}$-cell receptor-positive T cells and natural killer (NK) cells, is providing anti-tumor immunity and may help facilitate immune reconstitution posttransplant [5, 37]. Bertaina and colleagues recently reported updated data in pediatric patients with acute leukemia and showed that $\alpha \beta$ TCD HHCT was associated with a low incidence of acute and chronic GVHD, as well as better survival compared with unrelated donor transplants, in particular when the donor showed 1 or more HLA-disparity with the recipient [38].

\section{TCR (unmanipulated) haploidentical transplantation}

To avoid complexity and cost associated with an ex vivo manipulation of $\mathrm{T}$ cells, several platforms of HHCT using TCR graft with intensified post-transplant immunosuppression have been developed with promising results. These are widely adopted as TCR HHCT platforms.

\section{Post-transplantation cyclophosphamide}

Since the initial reports suggesting that high-dose cyclophosphamide given after AHCT could induce immunologic tolerance and suppress GVHD without causing global immunosuppression or graft failure [7, 39-42], several groups have successfully translated this approach into clinical practice [43, 44]. The main mechanism by which PTCy can induce immune tolerance lays on the selective elimination of host and donor alloreactive $\mathrm{T}$ cells, while sparing hematopoietic progenitor cells and regulatory $\mathrm{T}$ cells. The use of PTCy overcomes the need for extensive host and donor T-cell depletion to achieve sustained engraftment and effectively control GVHD, respectively, in HLA-partially mismatched AHCT, and has become the most common method used for GVHD prophylaxis in TCR HHCT [7]. 
GCSF-primed bone marrow and enhanced ATG-based GVHD prophylaxis

The group from Peking University first established HHCT based on G-CSF-primed bone marrow and peripheral blood graft and intensified, ATG-based GVHD prophylaxis with cyclosporine, mycophenolate mofetil, methotrexate and ATG [8, 15-17, 26-28]. Results obtained in both benign diseases and hematologic malignancies showed that the Beijing Protocol can provide comparable outcomes to those of HLA-identical sibling donor or unrelated donor transplantation [15-17, 26], suggesting a strong graft-versus-leukemia effect, while a higher incidence of chronic GVHD has been observed. Although primarily used in China, other centers in Asia and Europe have adopted this approach [45, 46].

All these HHCT platforms have been shown to be associated with very good outcomes and allow HHCT to be safely performed. However, differences in outcomes have been observed based on various donor types and careful selecting donors may further improve these outcomes. In addition, differences in the cost associated with different platforms and resource utilization remains the area unmet need and will need to be explored in the future.

\section{Donor characteristics influencing outcomes of haploidentical stem cell transplantation}

\section{Donor-specific anti-HLA antibodies}

Several studies have clearly confirmed the association of preformed donor-specific anti-HLA antibodies (DSAs) and the occurrence of primary graft failure in patients receiving AHCT, in particular in HLA-mismatched transplantation [47-50]. In HHCT, this issue can be more challenging especially in the child donor to mother recipient setting, since the recipient might be allosensitized and form antibodies against the non-shared donor's HLA antigens during pregnancy [48]. The incidence of DSAs in HHCT ranges between $\sim 10-21 \%$, being higher in females compared with male recipients [47-50]. A study from MD Anderson Cancer Center (MDACC) reported outcomes of 122 patients treated with both TCD and TCR HHCT, and showed a high incidence of DSAs (18\%) and a strong association with primary graft failure. Moreover, the time to engraftment was significantly delayed in patients with DSAs [48]. Likewise, Yoshihara and colleagues revealed that a high level of DSAs (>5000 MFI) was the only significant risk factor for graft failure in recipients of unmanipulated HHCT [49]. Beside primary graft failure and delayed engraftment, the development of DSAs was also found to be associated with primary poor graft function [50], and has negative impact survival post-transplant, not only in HHCT but also in other alternative donor transplants
[47-57]. The ability of DSAs to cause primary graft failure seems to depend on both antibody levels and activation of the complement system. The MDACC group demonstrated that DSAs that activate the complement system, detected by the clq assay, associate with high antibody levels and a very high likelihood of developing graft rejection, underlining the importance of antibody detection prior to HHCT [48]. Considering these evidences, EBMT now recommends routine testing for DSAs before choosing haploidentical donors for transplantation. Using hematopoietic stem cells from a donor without the corresponding HLA antigens is an ideal option for a recipient with HLA antibodies. However, if there are no such donors available, recipients with DSAs should undergo desensitization treatment prior to transplantation to prevent graft failure. Current approaches have been detailed recently in the recent EBMT consensus guidelines for detection and treatment of patients with DSAs in HHCT [58].

\section{Donor age}

Although donor age does not appear to be a limitation for the AHCT in HLA-matched transplants, transplantation using stem cells from a younger donor is strongly associated with a lower incidence of both acute and chronic GVHD, as well as with better survival [59-61]. The benefit of using a younger donor has been confirmed both in TCD and TCR HHCT. González-Vicent et al. showed an improved immune recovery, less acute GVHD, lower non-relapse mortality (NRM) and better disease-free survival (DFS) when using younger donors for pediatric patients with highrisk leukemia receiving CD3/CD19 and TCR $\alpha b+/ C D 19$ TCD HHCT [62]. In TCR HHCT, donor age has also been shown to influence outcomes of transplantation. Using the Beijing protocol, Wang et al. [27] found that donors younger than 30 years were significantly associated with lower NRM and better survival compared with older donors. The impact of donor age seems to be more relevant in older than in younger HHCT recipients. The most recent report on acute leukemia patients receiving TCR HHCT conducted by the Acute Leukemia Working Party (ALWP) of the EBMT demonstrated an increased NRM, inferior leukemia-free survival (LFS), overall survival (OS) and GVHD-free, relapse-free survival (GRFS) when patients over the age of 40 were transplanted using stem cells from an older donor, whereas donor age did not predict transplant outcomes in recipients younger than 40 years [63]. Likewise, Ciurea et al. found that younger donor age $(</=40$ years) was an independent predictor for better OS in older patients $(>/=55$ years) with $\mathrm{AML}$ and $\mathrm{MDS}$ receiving HHCT using PTCy for GVHD prophylaxis [64].

Although results from two other retrospective studies of HHCT with PTCy platform did not show a significant 
impact of donor age on transplant outcomes [65, 66], using a younger donor might provide additional benefits, including better CD34+ cell yield especially with a BM graft [67] and lower likelihood of clonal hematopoiesis, which can increase the risk of developing hematologic malignancies later in life in recipients of stem cells from older donors [68]. Moreover, younger donors are more likely to be physically fit and better tolerate the stem cell collection procedure and ensure that the procedure is perfectly safe for the donor.

\section{Donor gender}

It has been hypothesized that minor histocompatibility antigens (mHAgs) encoded on $\mathrm{Y}$ chromosome $(\mathrm{H}-\mathrm{Y})$ can be recognized by female donor $\mathrm{T}$ lymphocytes and may be responsible to an increased risk of GVHD and NRM in a setting of female donor to male recipient transplantation. However, this risk can be counterbalanced by the benefit of increasing graft-versus-tumor effect and a lower risk of relapse, since $\mathrm{H}-\mathrm{Y}$ antigen can also be expressed on tumor cells. This is particularly important in HLA-matched transplantation when minor HLAs are the main target of donor alloreactive $\mathrm{T}$ cells [69-71]. However, an adverse impact of using a female donor to a male recipient seems to be more pronounced in HLA-haplotype matched transplants. Kasamon et al. found that transplantation using a female donor to a male recipient resulted in lower survival after TCR HHCT using PTCy for GVHD prophylaxis. Although the negative impact on survival was not entirely accounted for by a significantly increased risk of GVHD, this finding still suggests that a male donor should be a preferred choice when selecting haploidentical donor for a male recipient, at least in a HHCT with PTCy platform [44].

The effect of donor gender on HHCT outcomes has also been explored outside the female to male transplant setting. Using the Beijing protocol of unmanipulated HHCT, Wang et al. showed that transplantation using a female donor was associated with a higher rate of severe acute GVHD, NRM and inferior survival. However, this negative impact was lost when mother donors were excluded from the analysis [27]. Mothers seem to be a poor donor choice for child recipients when using the Beijing protocol of HHCT as it was shown to be associated with higher rate of GVHD, NRM, and poor survival. In contrast, Stern et al. found that relapse rate and NRM were lower, resulting into better EFS in acute leukemia young patients who received TCD HHCT from a mother than from a father donor. The protective effect from using a mother donor was seen in both female and male recipients, while in a control cohort of patients who received transplants from haploidentical siblings, donor sex had no influence on outcome [72]. These apparently conflicting results suggest that perhaps donor relationship (mother donor) rather than donor gender has a stronger influence on transplant outcomes.

\section{Donor relationship and non-inherited maternal and paternal antigens (NIMA/NIPA)}

The effects of donor relationship on HHCT outcomes have been investigated in several studies [27, 65, 66, 73]. Focusing on TCR HHCT with PTCy, Solomon et al. [65] found that a parent donor (either maternal or paternal) resulted into a significantly higher risk of relapse and lower survival compared with a sibling or child donor, and the impact of donor relationship on outcomes persisted after adjusting for donor age. Moreover, a recent study by McCurdy and colleagues revealed a significantly higher risk of graft failure in patients who received haploidentical grafts from their parent, while graft failure risk was not different between sibling and offspring donors [66]. Taken together, these data suggest that an offspring or sibling donor is preferred over a parent donor for HHCT. However, conflicting results were seen when comparing outcomes with different parental donors.

It has been speculated that the benefit of mother-tochild transplantation may be the result of the maternal immune system exposure to paternal antigens from fetus during pregnancy, which can enhance graft-versus-tumor effect in a mother graft [69]. Moreover, child exposure to maternal antigens during in utero development or nursing can lead to a lifelong immunologic tolerance, preventing alloimmunization against maternal HLA antigens that the patient did not inherit such as in a setting of mother to child or non-inherited maternal antigens (NIMA) mismatched sibling donor transplants $[74,75]$. This evidence was first observed in kidney transplants; indeed kidney graft from haploidentical sibling mismatched for NIMA had similar graft survival with graft from an HLA-identical sibling donor [76]. In TCR HHCT, some studies have shown a lower risk of GVHD and TRM in patients receiving stem cell graft from a NIMA mismatched sibling donor than from a non-inherited paternal antigens (NIPA) mismatched sibling [27, 73, 77, 78]. The Chinese group found that NIMA mismatched sibling donor was associated with less acute GVHD when compared with NIPA mismatched sibling. Althogh NRM and survival were not influenced by NIMA/NIPA mismatching, NIMA mismatched siblings may be preferred over NIPA mismatched ones when using the Beijing protocol, at least to avoid the higher risk of acute GVHD [27]. However, whether this immunologic tolerance is associated with better outcomes in TCD and TCR HHCT using PTCy remains unclear.

Another aspect is the use of one-haplotype match second-degree related donors, especially younger donors, if 
no first degree related donor exists or the donor is too old or too young for donation. The Hopkins group has recently showed feasibility of using second-degree related donors with their non-myeloablative PTCy-based protocol [79]. Correspondingly, the Chinese group reported comparable survival outcome among recipients of a collateral and immediate haploidentical family donor using their transplant platform [80].

\section{$\mathrm{ABO}$ compatibility}

The impact of donor-recipient $\mathrm{ABO}$ compatibility on transplant outcomes has been evaluated in different transplant settings, and has shown different results [81-84]. In HLA matched related donor transplants, results from a meta-analysis revealed that $\mathrm{ABO}$ mismatched transplantation did not impact overall survival. However, minor and bidirectional ABO mismatched graft was associated with poor overall survival in patients receiving unrelated AHCT [81]. Additionally, the impact of $\mathrm{ABO}$ mismatch on transplant outcomes appears to be different in some studies, when using peripheral blood or bone marrow stem cell source. Logan et al., using data from Stanford University and the Center for International Blood and Marrow Transplant Research (CIBMTR), showed that ABO minor mismatched transplantation was associated with higher NRM and negatively affected survival only in patients receiving bone marrow but not peripheral blood stem cell grafts [85].

In HHCT setting, a large retrospective study from the ALWP of the EBMT demonstrated inferior engraftment rate in HHCT recipients who received a major $\mathrm{ABO}$ mismatch graft compared with $\mathrm{ABO}$ matched HHCT, whereas bi-directional $\mathrm{ABO}$ mismatching was found to be associated with a significantly increased risk of grade II-IV acute GVHD. Patients with major ABO mismatched grafts had decreased OS only when bone marrow-derived stem cell grafts were used, while $\mathrm{ABO}$ compatibility had no impact in patients who received peripheral blood grafts [86], in agreement with findings from the above-mentioned study by Logan et al. [85]. These results suggest that, at least in TCR HHCT with PTCy, patients with major ABO mismatched grafts should receive PB stem cells.

In addition to an adverse effect on survival, major $\mathrm{ABO}$ mismatch can also lead to hemolytic anemia, delayed red cell engraftment as well as pure red cell aplasia. Therefore a major $\mathrm{ABO}$ mismatched graft requires graft manipulation to decrease the amount of incompatible RBCs and to prevent hemolytic complications. This process could reduce the number of mononuclear cells, CD34+ and total nucleated cells in a bone marrow graft and perhaps negatively affect transplant outcomes [87].

In summary, the available evidence supports the use of an $\mathrm{ABO}$ compatible over a minor and/or a major $\mathrm{ABO}$ mismatched graft for TCR haploidentical donor transplants with PTCy. A peripheral blood graft is preferred in case of transplant from a major $\mathrm{ABO}$ incompatible donor when other donors are not available.

\section{NK cell alloreactivity}

NK cells are an important component of human innate immunity, recover early post-transplant and provide antitumor and antiviral effects during the period of severe lymphopenia. NK cell alloreactivity can potentially provide better antitumor effect, as documented by lower relapse rates and better survival in patients with higher NK cell numbers early posttransplant $[88,89]$. Cytotoxic activity of NK cells is mediated primarily by a balance between inhibitory and activating receptors expressed on the cell surface, the former being mainly accounted by killer-cell immunoglobulin-like receptors (KIRs) that recognize HLA class I molecules on surface of target cells. However, understanding of the biological determinants of anti-tumor effects of NK cells remains incomplete and conflicting evidence exists in the transplantation literature. Several models of donor-recipient NK cell alloreactivity have been proposed and studied in different settings of AHCT especially in HHCT, which may explain, at least in part, different results. The KIR ligand incompatibility (ligand-ligand) model, in which NK cells will react and kill host cells that lack the HLA class I ligand(s) for inhibitory KIR, was first proposed by the Perugia group [90]. Using this model in a clinical study of TCD HHCT, Ruggeri et al. [91] found that alloreactive NK cells in the graft-versus-host direction helped promote engraftment and graft-versus-tumor effect, resulted in reduced risk of leukemia relapse and better survival in adults with acute myeloid leukemia (AML) without increasing the rate of GVHD. Leung et al. proposed an alternative model called the receptor-ligand or missing-self model, according to which NK cells will react if at least one KIR gene expressed in the donor's NK cell repertoire does not recognize any of the HLA molecules in the recipient's ligand repertoire. In a study of pediatric patients with high-risk leukemia given $\mathrm{CD} 34+$ selected haploidentical graft, the authors found that NK alloreactivity based on this model more accurately predicted the lower risk of leukemia relapse than the ligand-ligand model [92].

KIR genes are organized in haplotypes and, although more than 80 different KIR haplotypes have been reported, two distinct groups (termed A and B) have been identified. The A haplotypes (found in around $20-25 \%$ of subjects) are characterized by a fixed number of KIR genes including several inhibitory KIR (KIR3DL3, KIR2DL3, KIR2DL1, KIR2DL4, KIR3DL1, and KIR3DL2), only one activating KIR (KIR2DS4), and the two pseudogenes (KIR2DP1 and KIR3DP1). In contrast, B haplotypes have variable and greater gene content, and are characterized by the presence 
of at least one of the following genes: KIR2DS2, KIR2DL2, KIR2DL5B, KIR3DS1, KIR2DL5A, KIR2DS3, KIR2DS5, and KIR2DS1. All individuals can be categorized as having 1 of 2 KIR genotypes: homozygous group A KIR haplotype (A/A) or having at least one group $\mathrm{B}$ haplotype $(\mathrm{B} / \mathrm{x})$. Michealis et al. [93] demonstrated a significantly reduced incidence of relapse in recipients of TCD HHCT receiving stem cell graft from a KIR haplotype Bx donor when compared with haplotype AA donor. A similar result was reported in a study of TCD HHCT for pediatric patients with ALL, confirming the survival benefit of using donor with KIR B haplotype [94, 95]. Mancusi and colleagues also showed a reduction of NRM in patients transplanted using a KIR B haplotype donor in comparison to those given a KIR A haplotype donor HHCT [92]. All abovementioned studies showing the benefit of NK alloreactivity using different models and of KIR B haplotype donors were conducted in TCD HHCT platforms, where donor T cells do not obscure the importance of the role played by NK cells, whereas the benefit of donor-recipient NK alloreactivity in TCR HHCT setting remains unclear since conflicting results have been recently reported. Solomon and colleagues showed that KIR mismatch using receptor-ligand model and group B KIR haplotype with the presence of KIR2DS2 were associated with reduced relapse rate and improvements in survival post-transplant [65]. Likewise, another recent study by Wanquet et al. revealed that the presence of donorrecipient KIR-ligand mismatch was associated with a lower incidence of relapse, which led to a significantly improved progression-free survival (PFS) and a trend for improved OS, while rate of acute and chronic GVHD did not significantly increase. However, this benefit was seen only in a subgroup of patients with active disease, but not in patients who were in remission at time of transplant [96]. Also, Symons et al. showed that recipients of inhibitory KIR gene-mismatched grafts had an improved OS, EFS and relapse rate in TCR HHCT with PTCy. Moreover, the authors also found that patients homozygous for the KIR A haplotype had an improved OS, EFS, and NRM if their donor expressed at least one KIR B haplotype [97]. Collectively, results from these studies revealed beneficial effects of NK cell alloreactivity, suggesting that selection of donors based upon NK cell alloreactivity may be warranted. On the contrary, a study by the EBMT group demonstrated that KIR ligand mismatching described by "the ligandligand" model was associated with a trend for higher relapse and significantly lower OS in recipients of TCR HHCT [98]. In accordance with these findings, Huang et al. [99] demonstrated that use of donors with KIR match rather than mismatch was associated with an improved NK-cell reconstitution quantitatively and functionally, resulting in a lower incidence of GVHD, relapse rate and a better survival in the setting of HHCT using the Beijing protocol. In addition, the Japanese group reported a similar relapse rate, NRM and OS between TCR HHCT patients receiving graft from either a KIR haplotype $\mathrm{A} / \mathrm{A}$ or $\mathrm{B} / \mathrm{x}$ donor, while using a donor with KIR haplotype $\mathrm{B} / \mathrm{x}$ was associated with a higher incidence of severe acute GVHD [100]. The reasons for these conflicting results perhaps come from the heterogeneity in transplant protocols employed and differences in inclusion criteria, as well as model used to describe NK cell alloreactivity.

However, taken together, a donor with alloreactive NK cells appears to be a preferred choice for patients receiving TCD HHCT, while more studies are needed to clarify this issue in TCR HHCT, especially when PTCy-based GVHD prophylaxis is employed. Recent work by Russo et al. [88] suggests that the majority of mature NK cells infused with unmanipulated grafts are lost upon PTCy administration likely resulting in the blunting NK cell alloreactivity in this setting.

\section{Donor-recipient CMV serostatus}

CMV infection/reactivation is a common complication after AHCT, which sometimes can be fatal and may negatively influence post-transplant outcomes [101]. Although the incidence of symptomatic CMV diseases has decreased significantly because of preemptive therapy [102-104], this infectious complication still develops in a significant proportion of all AHCT recipients, and it is influenced partly by the mismatch between donor and recipient CMV serostatus [105]. This issue may be more concerning in HHCT as more patients reactivate CMV in the setting of an HLAdisparate donor transplant, and more potent immunosuppression is needed to overcome the HLA barrier. Interestingly, the use of a CMV positive donor in AHCT has been shown to prevent CMV reactivation and improve outcome when administered to a CMV positive recipient $[101,106]$. This donor-recipient combination may be particularly important when used in the context of transplant strategies to eliminate $\mathrm{T}$ cells as encountered in TCD HHCT. Indeed, the immediate availability of $\mathrm{T}$ cells with anti-CMV reactivity may be useful to overcome CMV viral load early post-transplant when $\mathrm{T}$ cells are only present in low numbers.

However, conflicting results on the impact of donorrecipient CMV serostatus match on TCR HHCT outcomes have been reported to date. In a recent study, Solomon et al. [65] found that donor CMV-negative serostatus was associated with inferior survival, while a protective effect of a CMV-seropositive donor was limited to CMV-seropositive recipients. On the contrary, two retrospective studies failed to demonstrate any significant clinical impact of donor CMV serostatus after TCR HHCT $[66,107]$. Moreover, a report restricted to $983 \mathrm{CMV}$ seropositive recipients of TCR 
HHCT with PTCy from the EBMT group revealed that donor CMV serostatus did not influence NRM or OS [108]. Due to these conflicting results, it is difficult to conclude and make recommendations on TCR haploidentical donor selection based on donor-recipient CMV serostatus.

\section{Degree of HLA-mismatch}

Higher degree of HLA-mismatch between donor and recipient has been associated with a significantly increased TRM and poor survival after AHCT from both related and unrelated donors using conventional GVHD prophylaxis [109-111]. However, the adverse effect of donor-recipient HLA disparity appears to be reduced with the new approaches used for GVHD prophylaxis in HHCT. Kasamon and colleagues found that, in TCR HHCT using non-myeloablative conditioning with PTCy for GVHD prophylaxis, the presence of a greater number of HLA mismatches at either the antigen or allele level did not worsen overall outcomes with regards to GVHD, relapse and NRM. Besides that, having three or more HLAmismatches in the host-versus-graft (HVG) direction was associated with superior EFS [44]. These results suggest that greater HLA mismatch between the donor and the recipient is not associated with worse outcomes in HHCT. Similar findings were also reported in other studies of TCR HHCT using both PTCy and with the Beijing protocol. In these studies, the total number of HLA mismatches either bidirectional or in the GVH/HVG direction did not influence transplant outcomes [27, 65, 112-114]. Regarding the specific HLA allele and antigen mismatch, the most recent data from the EBMT demonstrated that an antigenic but not allelic mismatch at the HLA-DRB1 locus was an independent risk factor for severe acute GVHD in PTCy, but not in ATG regimens, suggesting that the role of HLA matching in HHCT might be modulated by GVHD prophylaxis [113]. Other studies found that the presence of an HLA-DRB1 mismatch in the graft-versus-host direction and HLA-DPB1 non-permissive mismatch were associated with an improvement in survival [65].

Taken together, these data do not support selection of haploidentical donors based on the degree of HLA mismatch. More data are needed to clarify the impact of specific HLA antigens/alleles on outcomes of HHCT as conflicting results have been reported to date.

\section{Special considerations regarding using minors as donors for haploidentical transplantation- Psychological aspects and potential conflict of interest}

It is clear that the increasing use of haploidentical donors will have to be accompanied by a strengthening of the psychological evaluation and will necessitate an increased training of caregiver teams. With the shift from unrelated to family donors, family dynamics and dormant tensions may be reactivated. Indeed, the transplant is very often experienced by the patient as an upheaval, not just in his or her own body, but also in relation to others, especially the nuclear family. From the donor's point of view, giving is a gift of self and an investment, especially in time but also symbolically. The challenge of choosing between several potential haploidentical related donors-mother, father, brother, sister or cousin, niece, nephew-will open up particularly complex elaborations and exchanges: teams will have to explain their choice and justify them. It will be important for the transplant team to establish a personal relationship with the donor and carefully/cautiously manage the psychological repercussions of complications occurring either during or after the transplant, especially in case of failure. Children who die of complications of a transplant of stem cells from their mother or a father, or patients who must live with chronic GVHD after a transplant of their child's cells might become common but new situations and inevitably, Oedipal updates will insistently color the dynamics of this type of transplant.

One of the major aspects regarding a minor donor for parents or siblings as recipients is the potential conflict of interest related to such donation. In this circumstance, several ethical challenging questions arise such as "are parents capable to make fair decisions regarding the donation in the best interests of their donor child, and not determined by interests of themselves or other family members?" or "should mature and immature children be treated differently regarding consent or assent to donate?" While regulations regarding minor donors differ between countries and regions, it is fundamental that practice recommendations and standards focusing on medical and psychological assessments and follow-up care for the donors are established by multi-disciplinary teams to ensure that donor's best interests in case of children are fully considered and acted upon. According to the FACT-JACIE international standards, a donor advocate different from the transplant recipient's primary treating physician should be available to represent allogeneic donors who are minors or who are mentally incapacitated, to help the donor understand the risks and benefits of donation, ensure that the consent is made without time pressure and with full information, and to aid in the resolution of subsequent problems both physically and psychologically [115]. In cases of using children as donors, in addition to evaluation by a Pediatrician, a medical ethicist should probably be involved to provide an unbiased assessment and help facilitation the donation. 
Table 1 Summary of characteristics considered in selecting donors for haploidentical hematopoietic cell transplantation

\begin{tabular}{ll}
\hline T cell depleted haploidentical transplants & T cell replete haploidentical transplants \\
\hline -No DSAs (MFI < 1000) & -No DSAs $(\mathrm{MFI}<1000)$ \\
-NK cell alloreactive donor & -Younger donor over older donor \\
-Younger donor over older donor & -Male donor for a male recipient \\
-Male donor for a male recipient & -Sibling or offspring donor over parent donor \\
-First degree relative over second degree HLA & -Between parent donors, father is preferred over mother \\
half-matched donor & donor \\
-Between parent donors, mother is preferred & -ABO matched is preferred to minor ABO mismatch to \\
over father & major ABO mismatched donor \\
-ABO matched donor & -Donor with KIR ligand match for a recipient of HHCT \\
-CMV seropositive donor for CMV & -First degree relative over second degree HLA half- \\
seropositive recipients & matched donor
\end{tabular}

-Donor with NIMA mismatch over NIPA mismatch for a recipient of $\mathrm{HHCT}^{\mathrm{a}}$

DSA donor-specific anti-HLA antibodies, $N K$ natural killer cells, $H H C T$ haploidentical hematopoietic cell transplantation, NIMA non-inherited maternal antigens, $A B O$ blood group

${ }^{a}$ Conclusive data available for the TCR Haploidentical transplants with GCSF-primed bone marrow and enhanced GVHD prophylaxis (Beijing protocol)

\section{Conclusions and summary recommendations}

It is now clear that HHCT can provide the chance of a cure for many patients who lack an HLA-matched donor, including especially ethnic minorities, with similar results to those reported using an HLA-matched donor. This development has become one of the most important success stories in transplantation and probably in modern medicine. Among several factors responsible for the success of HHCT, donor considerations are particularly important when more than one potential HLA-haploidentical donor might be available for transplantation, and multiple donor factors can impact transplant outcomes. Therefore, the EBMT has formed an expert panel charged to summarize the recommendations for selection of a haploidentical donors based on available published data for all HHCT platforms used in clinical practice (Table 1). Although it is likely that this field will further evolve in the future, enough work has been done to date to provide a comprehensive overview of this topic right now. Below we have summarized our recommendations in a still preliminary order of importance.

\section{Summary of preferred donor characteristics for T-cell depleted haploidentical transplants}

1. For a recipient with DSAs, a donor without corresponding HLA antigen is preferred

2. NK cell alloreactive donor if available

3. Younger donor over older donor
4. A male donor for a male recipient

5. First degree relative over second degree HLA halfmatched donor

6. Between parent donors, mother is preferred over father

7. $\mathrm{ABO}$ matched donor

8. CMV seropositive donor for CMV seropositive recipients

\section{Summary of preferred donor characteristics for $T$ cell replete haploidentical transplants}

1. For a recipient with DSAs, a donor without corresponding HLA antigen is preferred

2. Younger donor over older donor

3. A male donor for a male recipient

4. Sibling or offspring donor over parent donor

5. Between parent donors, father is preferred over mother donor

6. $\mathrm{ABO}$ matched to minor $\mathrm{ABO}$ mismatch to major $\mathrm{ABO}$ mismatched donor

7. First degree relative over second degree HLA halfmatched donor (Beijing protocol)

8. Donor with KIR ligand match for a recipient of HHCT (Beijing protocol)

9. Donor with NIMA mismatch over NIPA mismatch for a recipient of HHCT (Beijing protocol)

\section{Compliance with ethical standards}

Conflict of interest The authors declare that they have no conflict of interest. 
Publisher's note: Springer Nature remains neutral with regard to jurisdictional claims in published maps and institutional affiliations.

\section{References}

1. Niederwieser D, Baldomero H, Szer J, Gratwohl M, Aljurf M, Atsuta $\mathrm{Y}$, et al. Hematopoietic stem cell transplantation activity worldwide in 2012 and a SWOT analysis of the Worldwide Network for Blood and Marrow Transplantation Group including the global survey. Bone Marrow Transplant. 2016;51:778-85.

2. Passweg JR, Baldomero H, Bader P, Bonini C, Duarte RF, Dufour $\mathrm{C}$, et al. Use of haploidentical stem cell transplantation continues to increase: the 2015 European Society for Blood and Marrow Transplant activity survey report. Bone Marrow Transplant. 2017;52:811-7.

3. Aversa F, Terenzi A, Tabilio A, Falzetti F, Carotti A, Ballanti S, et al. Full haplotype-mismatched hematopoietic stem-cell transplantation: a phase II study in patients with acute leukemia at high risk of relapse. J Clin Oncol. 2005;23:3447-54.

4. Martelli MF, Di Ianni M, Ruggeri L, Falzetti F, Carotti A, Terenzi A, et al. HLA-haploidentical transplantation with regulatory and conventional T-cell adoptive immunotherapy prevents acute leukemia relapse. Blood. 2014;124:638-44.

5. Locatelli F, Merli P, Pagliara D, Li Pira G, Falco M, Pende D, et al. Outcome of children with acute leukemia given HLAhaploidentical HSCT after alphabeta T-cell and B-cell depletion. Blood. 2017;130:677-85.

6. Roy D-C, Lachance S, Roy J, Walker I, Maertens J, Delisle J-S, et al. Donor Lymphocytes Depleted of Alloreactive T-Cells (ATIR101) Improve Event-Free Survival (GRFS) and Overall Survival in a T-Cell Depleted Haploidentical HSCT: Phase 2 Trial in Patients with AML and ALL. Blood. 2016;128:1226.

7. Luznik L, O'Donnell PV, Symons HJ, Chen AR, Leffell MS, Zahurak M, et al. HLA-haploidentical bone marrow transplantation for hematologic malignancies using nonmyeloablative conditioning and high-dose, posttransplantation cyclophosphamide. Biol Blood Marrow Transplant. 2008;14:641-50.

8. Huang XJ, Liu DH, Liu KY, Xu LP, Chen H, Han W, et al. Haploidentical hematopoietic stem cell transplantation without in vitro T-cell depletion for the treatment of hematological malignancies. Bone Marrow Transplant. 2006;38:291-7.

9. Raiola AM, Dominietto A, Ghiso A, Di Grazia C, Lamparelli T, Gualandi F, et al. Unmanipulated haploidentical bone marrow transplantation and posttransplantation cyclophosphamide for hematologic malignancies after myeloablative conditioning. Biol Blood Marrow Transplant. 2013;19:117-22.

10. Bacigalupo A, Dominietto A, Ghiso A, Di Grazia C, Lamparelli T, Gualandi $\mathrm{F}$, et al. Unmanipulated haploidentical bone marrow transplantation and post-transplant cyclophosphamide for hematologic malignanices following a myeloablative conditioning: an update. Bone Marrow Transplant. 2015;50(Suppl 2):S37-9.

11. Bashey A, Zhang X, Sizemore CA, Manion K, Brown S, Holland HK, et al. T-cell-replete HLA-haploidentical hematopoietic transplantation for hematologic malignancies using post-transplantation cyclophosphamide results in outcomes equivalent to those of contemporaneous HLA-matched related and unrelated donor transplantation. J Clin Oncol. 2013;31:1310-6.

12. Ciurea SO, Zhang MJ, Bacigalupo AA, Bashey A, Appelbaum FR, Aljitawi OS, et al. Haploidentical transplant with posttransplant cyclophosphamide vs matched unrelated donor transplant for acute myeloid leukemia. Blood. 2015;126:1033-40.
13. Ghosh N, Karmali R, Rocha V, Ahn KW, DiGilio A, Hari PN, et al. Reduced-intensity transplantation for lymphomas using haploidentical related donors versus HLA-matched sibling donors: A Center for International Blood and Marrow Transplant Research Analysis. J Clin Oncol. 2016;34:3141-9.

14. Robinson TM, Fuchs EJ, Zhang MJ, St Martin A, Labopin M, Keesler DA, et al. Related donor transplants: has posttransplantation cyclophosphamide nullified the detrimental effect of HLA mismatch? Blood Adv. 2018;2:1180-6.

15. Wang Y, Liu QF, Xu LP, Liu KY, Zhang XH, Ma X, et al. Haploidentical vs identical-sibling transplant for AML in remission: a multicenter, prospective study. Blood. 2015;125:3956-62.

16. Wang Y, Wang HX, Lai YR, Sun ZM, Wu DP, Jiang M, et al. Haploidentical transplant for myelodysplastic syndrome: registry-based comparison with identical sibling transplant. Leukemia. 2016;30:2055-63.

17. Wang Y, Liu QF, Xu LP, Liu KY, Zhang XH, Ma X, et al. Haploidentical versus Matched-Sibling Transplant in Adults with Philadelphia-Negative High-Risk Acute Lymphoblastic Leukemia: A Biologically Phase III Randomized Study. Clin Cancer Res. 2016;22:3467-76.

18. Lorentino F, Labopin M, Bernardi M, Ciceri F, Socie G, Cornelissen JJ, et al. Comparable outcomes of haploidentical, $10 / 10$ and $9 / 10$ unrelated donor transplantation in adverse karyotype AML in first complete remission. Am J Hematol. 2018;93:1236-44.

19. Santoro N, Labopin M, Giannotti F, Ehninger G, Niederwieser $\mathrm{D}$, Brecht A, et al. Unmanipulated haploidentical in comparison with matched unrelated donor stem cell transplantation in patients 60 years and older with acute myeloid leukemia: a comparative study on behalf of the ALWP of the EBMT. J Hematol Oncol. 2018;11:55.

20. Fuchs EJ. Haploidentical transplantation for hematologic malignancies: where do we stand? Hematol Am Soc Hematol Educ Program. 2012;2012:230-6.

21. Bastien JP, Krosl G, Therien C, Rashkovan M, Scotto C, Cohen $\mathrm{S}$, et al. Photodepletion differentially affects CD4 + Tregs versus CD4 + effector T cells from patients with chronic graft-versushost disease. Blood. 2010;116:4859-69.

22. Bertaina A, Merli P, Rutella S, Pagliara D, Bernardo ME, Masetti R, et al. HLA-haploidentical stem cell transplantation after removal of alphabeta $+\mathrm{T}$ and $\mathrm{B}$ cells in children with nonmalignant disorders. Blood. 2014;124:822-6.

23. Ciceri F, Labopin M, Aversa F, Rowe JM, Bunjes D, Lewalle P, et al. A survey of fully haploidentical hematopoietic stem cell transplantation in adults with high-risk acute leukemia: a risk factor analysis of outcomes for patients in remission at transplantation. Blood. 2008;112:3574-81.

24. Solomon SR, Sizemore CA, Sanacore M, Zhang X, Brown S, Holland HK, et al. Haploidentical transplantation using $\mathrm{T}$ cell replete peripheral blood stem cells and myeloablative conditioning in patients with high-risk hematologic malignancies who lack conventional donors is well tolerated and produces excellent relapse-free survival: results of a prospective phase II trial. Biol Blood Marrow Transplant. 2012;18:1859-66.

25. Kongtim P, Pingali SR, Jimenez AM, Rondon G, Chen J, Oran B, et al. Haploidentical transplantation (HaploSCT) with posttransplant cyclophosphamide (PTCy) and melphalan-based conditioning: a retrospective analysis of the first 100 patients treated at MD Anderson Cancer Center. ASCO Meet Abstr. 2014;32(15_suppl):7017.

26. Chang YJ, Wang Y, Liu YR, Xu LP, Zhang XH, Chen H, et al. Haploidentical allograft is superior to matched sibling donor allograft in eradicating pre-transplantation minimal residual disease of AML patients as determined by multiparameter flow 
cytometry: a retrospective and prospective analysis. J Hematol Oncol. 2017;10:134.

27. Wang Y, Chang YJ, Xu LP, Liu KY, Liu DH, Zhang XH, et al. Who is the best donor for a related HLA haplotype-mismatched transplant? Blood. 2014;124:843-50.

28. Al Malki MM, Horowitz M, Handgretinger R, Leung W, Roy DC, Huang XJ, et al. Proceedings from the Second Haploidentical Stem Cell Transplantation Symposium-Haplo2014, San Francisco, California, December 4, 2014. Biol Blood Marrow Transplant. 2016;22:594-604.

29. O'Reilly RJ, Keever C, Kernan NA, Brochstein J, Collins N, Flomenberg N, et al. HLA nonidentical T cell depleted marrow transplants: a comparison of results in patients treated for leukemia and severe combined immunodeficiency disease. Transplant Proc. 1987;19(6 Suppl 7):55-60.

30. Ash RC, Horowitz MM, Gale RP, van Bekkum DW, Casper JT, Gordon-Smith EC, et al. Bone marrow transplantation from related donors other than HLA-identical siblings: effect of T cell depletion. Bone Marrow Transplant. 1991;7:443-52.

31. Ciurea SO, Mulanovich V, Jiang Y, Bassett R, Rondon G, McMannis $J$, et al. Lymphocyte recovery predicts outcomes in cord blood and $\mathrm{T}$ cell-depleted haploidentical stem cell transplantation. Biol Blood Marrow Transplant. 2011;17:1169-75.

32. Ciurea SO, Saliba R, Rondon G, Pesoa S, Cano P, FernandezVina M, et al. Reduced-intensity conditioning using fludarabine, melphalan and thiotepa for adult patients undergoing haploidentical SCT. Bone Marrow Transplant. 2010;45:429-36.

33. Di Stasi A, Tey SK, Dotti G, Fujita Y, Kennedy-Nasser A, Martinez C, et al. Inducible apoptosis as a safety switch for adoptive cell therapy. N Eng J Med. 2011;365:1673-83.

34. Bastien JP, Roy J, Roy DC. Selective T-cell depletion for haplotype-mismatched allogeneic stem cell transplantation. Semin Oncol. 2012;39:674-82.

35. Ciceri F, Bonini C, Stanghellini MT, Bondanza A, Traversari C, Salomoni M, et al. Infusion of suicide-gene-engineered donor lymphocytes after family haploidentical haemopoietic stem-cell transplantation for leukaemia (the TK007 trial): a nonrandomised phase I-II study. Lancet Oncol. 2009;10:489-500.

36. Blazar BR, Murphy WJ, Abedi M. Advances in graft-versus-host disease biology and therapy. Nat Rev Immunol. 2012;12:443-58.

37. Li Pira G, Malaspina D, Girolami E, Biagini S, Cicchetti E, Conflitti G, et al. Selective depletion of alphabeta T cells and B cells for human leukocyte antigen-haploidentical hematopoietic stem cell transplantation. A three-year follow-up of procedure efficiency. Biol Blood Marrow Transplant. 2016;22:2056-64.

38. Bertaina A, Zecca M, Buldini B, Sacchi N, Algeri M, Saglio F, et al. Unrelated donor vs HLA-haploidentical alpha/beta T-cell and B-cell depleted HSCT in children with acute leukemia. Blood 2018;132:2594-607.

39. Berenbaum MC, Brown IN. Prolongation of homograft survival in mice with single doses of cyclophosphamide. Nature. 1963;200:84.

40. Santos GW, Owens AH. Production of graft-versus-host disease in the rat and its treatment with cytotoxic agents. Nature. 1966;210:139-40.

41. Mayumi H, Good RA. Long-lasting skin allograft tolerance in adult mice induced across fully allogeneic (multimajor $\mathrm{H}-2$ plus multiminor histocompatibility) antigen barriers by a tolerance-inducing method using cyclophosphamide. J Exp Med. 1989;169:213-38.

42. Luznik L, Jalla S, Engstrom LW, Iannone R, Fuchs EJ. Durable engraftment of major histocompatibility complex-incompatible cells after nonmyeloablative conditioning with fludarabine, lowdose total body irradiation, and posttransplantation cyclophosphamide. Blood. 2001;98:3456-64.

43. O'Donnell PV, Luznik L, Jones RJ, Vogelsang GB, Leffell MS, Phelps M, et al. Nonmyeloablative bone marrow transplantation from partially HLA-mismatched related donors using posttransplantation cyclophosphamide. Biol Blood Marrow Transplant. 2002;8:377-86.

44. Kasamon YL, Luznik L, Leffell MS, Kowalski J, Tsai HL, Bolanos-Meade J, et al. Nonmyeloablative HLA-haploidentical bone marrow transplantation with high-dose posttransplantation cyclophosphamide: effect of HLA disparity on outcome. Biol Blood Marrow Transplant. 2010;16:482-9.

45. Kanakry CG, Fuchs EJ, Luznik L. Modern approaches to HLAhaploidentical blood or marrow transplantation. Nature reviews. Clin Oncol (R Coll Radiol). 2016;13:10-24.

46. Di Bartolomeo P, Santarone S, De Angelis G, Picardi A, Cudillo L, Cerretti R, et al. Haploidentical, unmanipulated, G-CSFprimed bone marrow transplantation for patients with high-risk hematologic malignancies. Blood. 2013;121:849-57.

47. Ciurea SO, de Lima M, Cano P, Korbling M, Giralt S, Shpall EJ, et al. High risk of graft failure in patients with anti-HLA antibodies undergoing haploidentical stem-cell transplantation. Transplantation. 2009;88:1019-24.

48. Ciurea SO, Thall PF, Milton DR, Barnes TH, Kongtim P, Carmazzi $\mathrm{Y}$, et al. Complement-binding donor-specific anti-HLA antibodies and risk of primary graft failure in hematopoietic stem cell transplantation. Biol Blood Marrow Transplant. 2015;21:1392-8.

49. Yoshihara S, Maruya E, Taniguchi K, Kaida K, Kato R, Inoue T, et al. Risk and prevention of graft failure in patients with preexisting donor-specific HLA antibodies undergoing unmanipulated haploidentical SCT. Bone Marrow Transplant. 2012;47:508-15.

50. Chang YJ, Zhao XY, Xu LP, Zhang XH, Wang Y, Han W, et al. Donor-specific anti-human leukocyte antigen antibodies were associated with primary graft failure after unmanipulated haploidentical blood and marrow transplantation: a prospective study with randomly assigned training and validation sets. J Hematol Oncol. 2015;8:84.

51. Spellman S, Bray R, Rosen-Bronson S, Haagenson M, Klein J, Flesch $S$, et al. The detection of donor-directed, HLA-specific alloantibodies in recipients of unrelated hematopoietic cell transplantation is predictive of graft failure. Blood. 2010;115:2704-8.

52. Ciurea SO, Thall PF, Wang X, Wang SA, Hu Y, Cano P, et al. Donor-specific anti-HLA Abs and graft failure in matched unrelated donor hematopoietic stem cell transplantation. Blood. 2011;118:5957-64.

53. Brunstein CG, Noreen H, DeFor TE, Maurer D, Miller JS, Wagner JE. Anti-HLA antibodies in double umbilical cord blood transplantation. Biol Blood Marrow Transplant. 2011;17:1704-8.

54. Cutler C, Kim HT, Sun L, Sese D, Glotzbecker B, Armand P, et al. Donor-specific anti-HLA antibodies predict outcome in double umbilical cord blood transplantation. Blood. 2011;118:6691-7.

55. Takanashi M, Atsuta Y, Fujiwara K, Kodo H, Kai S, Sato H, et al. The impact of anti-HLA antibodies on unrelated cord blood transplantations. Blood. 2010;116:2839-46.

56. Ruggeri A, Rocha V, Masson E, Labopin M, Cunha R, Absi L, et al. Impact of donor-specific anti-HLA antibodies on graft failure and survival after reduced intensity conditioningunrelated cord blood transplantation: a Eurocord, Societe Francophone d'Histocompatibilite et d'Immunogenetique (SFHI) and Societe Francaise de Greffe de Moelle et de Therapie Cellulaire (SFGM-TC) analysis. Haematologica . 2013;98:1154-60.

57. Takanashi M, Fujiwara K, Tanaka H, Satake M, Nakajima K. The impact of HLA antibodies on engraftment of unrelated cord blood transplants. Transfusion. 2008;48:791-3.

58. Ciurea SO, Cao K, Fernadez-Vina M, Kongtim P, Malki MA, Fuchs E, et al. The European Society for Blood and Marrow Transplantation (EBMT) Consensus Guidelines for the Detection and Treatment of Donor-specific Anti-HLA Antibodies (DSA) in Haploidentical Hematopoietic Cell Transplantation. Bone Marrow Transplant. 2018;53:521-34. 
59. Kollman C, Howe CW, Anasetti C, Antin JH, Davies SM, Filipovich $\mathrm{AH}$, et al. Donor characteristics as risk factors in recipients after transplantation of bone marrow from unrelated donors: the effect of donor age. Blood. 2001;98:2043-51.

60. Eisner MD, August CS. Impact of donor and recipient characteristics on the development of acute and chronic graft-versushost disease following pediatric bone marrow transplantation. Bone Marrow Transplant. 1995;15:663-8.

61. Bastida JM, Cabrero M, Lopez-Godino O, Lopez-Parra M, Sanchez-Guijo F, Lopez-Corral L, et al. Influence of donor age in allogeneic stem cell transplant outcome in acute myeloid leukemia and myelodisplastic syndrome. Leuk Res. 2015;39:828-34.

62. Gonzalez-Vicent M, Molina B, Deltoro N, Sevilla J, Vicario JL, Castillo A, et al. Donor age matters in T-cell depleted haploidentical hematopoietic stem cell transplantation in pediatric patients: faster immune reconstitution using younger donors. Leuk Res. 2017;57:60-4.

63. Canaani J, Savani BN, Labopin M, Huang XJ, Ciceri F, Arcese $\mathrm{W}$, et al. Donor age determines outcome in acute leukemia patients over 40 undergoing haploidentical hematopoietic cell transplantation. Am J Hematol. 2018;93:246-53.

64. Ciurea SO, Shah MV, Saliba RM, Gaballa S, Kongtim P, Rondon $\mathrm{G}$, et al. Haploidentical transplantation for older patients with acute myeloid leukemia and myelodysplastic syndrome. Biol Blood Marrow Transplant. 2018;24:1232-6.

65. Solomon SR, Aubrey MT, Zhang X, Piluso A, Freed BM, Brown $\mathrm{S}$, et al. Selecting the best donor for haploidentical transplant: impact of HLA, killer cell immunoglobulin-like receptor genotyping, and other clinical variables. Biol Blood Marrow Transplant. 2018;24:789-98.

66. McCurdy SR, Zhang MJ, St Martin A, Al Malki MM, Bashey A, Gaballa S, et al. Effect of donor characteristics on haploidentical transplantation with posttransplantation cyclophosphamide. Blood Adv. 2018;2:299-307.

67. Zhang C, Chen XH, Zhang X, Gao L, Gao L, Kong PY, et al. Stem cell collection in unmanipulated HLA-haploidentical/mismatched related transplantation with combined granulocyte-colony stimulating factor-mobilised blood and bone marrow for patients with haematologic malignancies: the impact of donor characteristics and procedural settings. Transfus Med. 2010;20:169-77.

68. Jaiswal S, Fontanillas P, Flannick J, Manning A, Grauman PV, Mar BG, et al. Age-related clonal hematopoiesis associated with adverse outcomes. N Eng J Med. 2014;371:2488-98.

69. Frassoni F, Labopin M, Gluckman E, Prentice HG, Vernant JP, Zwaan $\mathrm{F}$, et al. Results of allogeneic bone marrow transplantation for acute leukemia have improved in Europe with time-a report of the acute leukemia working party of the European group for blood and marrow transplantation (EBMT). Bone Marrow Transplant. 1996;17:13-8.

70. Stern M, Brand R, de Witte T, Sureda A, Rocha V, Passweg J, et al. Female-versus-male alloreactivity as a model for minor histocompatibility antigens in hematopoietic stem cell transplantation. Am J Transplant. 2008;8:2149-57.

71. Kongtim P, Di Stasi A, Rondon G, Chen J, Adekola K, Popat U, et al. Can a female donor for a male recipient decrease the relapse rate for patients with acute myeloid leukemia treated with allogeneic hematopoietic stem cell transplantation? Biol Blood Marrow Transplant. 2015;21:713-9.

72. Stern M, Ruggeri L, Mancusi A, Bernardo ME, de Angelis C, Bucher C, et al. Survival after T cell-depleted haploidentical stem cell transplantation is improved using the mother as donor. Blood. 2008;112:2990-5.

73. van Rood JJ, Loberiza FR Jr., Zhang MJ, Oudshoorn M, Claas F, Cairo MS, et al. Effect of tolerance to noninherited maternal antigens on the occurrence of graft-versus-host disease after bone marrow transplantation from a parent or an HLA-haploidentical sibling. Blood. 2002;99:1572-7.

74. van Rood JJ, Zhang L, van Leeuwen A, Claas FH. Neonatal tolerance revisited. Immunol Lett. 1989;21:51-4.

75. Claas F, Gijbels Y, van der Velden-de Munck J, van Rood J. Induction of B cell unresponsiveness to noninherited maternal HLA antigens during fetal life. Science. 1988;241:1815-7.

76. Burlingham WJ, Grailer AP, Heisey DM, Claas FH, Norman D, Mohanakumar T, et al. The effect of tolerance to noninherited maternal HLA antigens on the survival of renal transplants from sibling donors. N Eng J Med. 1998;339:1657-64.

77. Polchi P, Lucarelli G, Galimberti M, Giardini C, Baronciani D, Angelucci E, et al. Haploidentical bone marrow transplantation from mother to child with advanced leukemia. Bone Marrow Transplant. 1995;16:529-35.

78. Tamaki S, Ichinohe T, Matsuo K, Hamajima N, Hirabayashi N, Dohy H. Superior survival of blood and marrow stem cell recipients given maternal grafts over recipients given paternal grafts. Bone Marrow Transplant. 2001;28:375-80.

79. Elmariah H, Kasamon YL, Zahurak M, Macfarlane KW, Tucker $\mathrm{N}$, Rosner GL, et al. Haploidentical bone marrow transplantation with post-transplant cyclophosphamide using non-first-degree related donors. Biol Blood Marrow Transplant. 2018;24:1099-102.

80. Zhang YY, Liu DH, Liu KY, Xu LP, Chen H, Han W, et al. HLA-haploidentical hematopoietic SCT from collateral related donors without in vitro T-cell depletion for hematological malignancies. Bone Marrow Transplant. 2014;49:496-501.

81. Kanda J, Ichinohe T, Matsuo K, Benjamin RJ, Klumpp TR, Rozman $\mathrm{P}$, et al. Impact of ABO mismatching on the outcomes of allogeneic related and unrelated blood and marrow stem cell transplantations for hematologic malignancies: IPD-based metaanalysis of cohort studies. Transfusion. 2009;49:624-35.

82. Benjamin RJ, McGurk S, Ralston MS, Churchill WH, Antin $\mathrm{JH}$. ABO incompatibility as an adverse risk factor for survival after allogeneic bone marrow transplantation. Transfusion. 1999;39:179-87.

83. Goldman J, Liesveld J, Nichols D, Heal J, Blumberg N. ABO incompatibility between donor and recipient and clinical outcomes in allogeneic stem cell transplantation. Leuk Res. 2003;27:489-91.

84. Stussi G, Muntwyler J, Passweg JR, Seebach L, Schanz U, Gmur J, et al. Consequences of ABO incompatibility in allogeneic hematopoietic stem cell transplantation. Bone Marrow Transplant. 2002;30:87-93.

85. Logan AC, Wang Z, Alimoghaddam K, Wong RM, Lai T, Negrin RS, et al. ABO mismatch is associated with increased nonrelapse mortality after allogeneic hematopoietic cell transplantation. Biol Blood Marrow Transplant. 2015;21:746-54.

86. Canaani J, Savani BN, Labopin M, Huang XJ, Ciceri F, Arcese $\mathrm{W}$, et al. Impact of ABO incompatibility on patients' outcome after haploidentical hematopoietic stem cell transplantation for acute myeloid leukemia - a report from the Acute Leukemia Working Party of the EBMT. Haematologica. 2017;102:1066-74.

87. Scholl S, Klink A, Mugge LO, Schilling K, Hoffken K, Sayer HG. Safety and impact of donor-type red blood cell transfusion before allogeneic peripheral blood progenitor cell transplantation with major ABO mismatch. Transfusion. 2005;45:1676-83.

88. Russo A, Oliveira G, Berglund S, Greco R, Gambacorta V, Cieri $\mathrm{N}$, et al. NK cell recovery after haploidentical HSCT with posttransplant cyclophosphamide: dynamics and clinical implications. Blood. 2018;131:247-62.

89. Savani BN, Mielke S, Adams S, Uribe M, Rezvani K, Yong AS, et al. Rapid natural killer cell recovery determines outcome after T-cell-depleted HLA-identical stem cell transplantation in patients with myeloid leukemias but not with acute lymphoblastic leukemia. Leukemia. 2007;21:2145-52. 
90. Ruggeri L, Capanni M, Casucci M, Volpi I, Tosti A, Perruccio K, et al. Role of natural killer cell alloreactivity in HLA-mismatched hematopoietic stem cell transplantation. Blood. 1999;94:333-9.

91. Ruggeri L, Capanni M, Urbani E, Perruccio K, Shlomchik WD, Tosti A, et al. Effectiveness of donor natural killer cell alloreactivity in mismatched hematopoietic transplants. Science. 2002;295:2097-100.

92. Leung W, Iyengar R, Turner V, Lang P, Bader P, Conn P, et al. Determinants of antileukemia effects of allogeneic NK cells. J Immunol. 2004;172:644-50.

93. Michaelis SU, Mezger M, Bornhauser M, Trenschel R, Stuhler G, Federmann B, et al. KIR haplotype B donors but not KIR-ligand mismatch result in a reduced incidence of relapse after haploidentical transplantation using reduced intensity conditioning and CD3/CD19-depleted grafts. Ann Hematol. 2014;93:1579-86.

94. Oevermann L, Michaelis SU, Mezger M, Lang P, Toporski J, Bertaina A, et al. KIR B haplotype donors confer a reduced risk for relapse after haploidentical transplantation in children with ALL. Blood. 2014;124:2744-7.

95. Mancusi A, Ruggeri L, Urbani E, Pierini A, Massei MS, Carotti A, et al. Haploidentical hematopoietic transplantation from KIR ligand-mismatched donors with activating KIRs reduces nonrelapse mortality. Blood. 2015;125:3173-82.

96. Wanquet A, Bramanti S, Harbi S, Furst S, Legrand F, Faucher C, et al. Killer cell immunoglobulin-like receptor-ligand mismatch in donor versus recipient direction provides better graft-versustumor effect in patients with hematologic malignancies undergoing allogeneic $\mathrm{T}$ cell-replete haploidentical transplantation followed by post-transplant cyclophosphamide. Biol Blood Marrow Transplant. 2018;24:549-54.

97. Symons HJ, Leffell MS, Rossiter ND, Zahurak M, Jones RJ, Fuchs EJ. Improved survival with inhibitory killer immunoglobulin receptor (KIR) gene mismatches and KIR haplotype B donors after nonmyeloablative, HLA-haploidentical bone marrow transplantation. Biol Blood Marrow Transplant. 2010;16:533-42.

98. Shimoni A, Labopin M, Lorentino F, Van Lint MT, Koc Y, Gulbas $\mathrm{Z}$, et al. Killer cell immunoglobulin-like receptor ligand mismatching and outcome after haploidentical transplantation with post-transplant cyclophosphamide. Leukemia. 2019;33:230-9.

99. Huang XJ, Zhao XY, Liu DH, Liu KY, Xu LP. Deleterious effects of KIR ligand incompatibility on clinical outcomes in haploidentical hematopoietic stem cell transplantation without in vitro T-cell depletion. Leukemia. 2007;21:848-51.

100. Hosokai R, Masuko M, Shibasaki Y, Saitoh A, Furukawa T, Imai C. Donor killer immunoglobulin-like receptor haplotype $\mathrm{B} / \mathrm{x}$ induces severe acute graft-versus-host disease in the presence of human leukocyte antigen mismatch in $\mathrm{T}$ cell-replete hematopoietic cell transplantation. Biol Blood Marrow Transplant. 2017;23:606-11.

101. Ljungman P, Brand R, Hoek J, de la Camara R, Cordonnier C, Einsele $\mathrm{H}$, et al. Donor cytomegalovirus status influences the outcome of allogeneic stem cell transplant: a study by the European group for blood and marrow transplantation. Clin Infect Dis. 2014;59:473-81.

102. Di Stasi A, Milton DR, Poon LM, Hamdi A, Rondon G, Chen J, et al. Similar transplantation outcomes for acute myeloid leukemia and myelodysplastic syndrome patients with haploidentical versus 10/10 human leukocyte antigen-matched unrelated and related donors. Biol Blood Marrow Transplant. 2014;20:1975-81.
103. Chemaly RF, Ullmann AJ, Stoelben S, Richard MP, Bornhauser M, Groth C, et al. Letermovir for cytomegalovirus prophylaxis in hematopoietic-cell transplantation. $\mathrm{N}$ Eng $\mathrm{J}$ Med. 2014;370:1781-9.

104. Marty FM, Ljungman P, Chemaly RF, Maertens J, Dadwal SS, Duarte RF, et al. Letermovir prophylaxis for cytomegalovirus in hematopoietic-cell transplantation. N Eng J Med. 2017; 377:2433-44.

105. Matthes-Martin S, Lion T, Aberle SW, Fritsch G, Lawitschka A, Bittner B, et al. Pre-emptive treatment of CMV DNAemia in paediatric stem cell transplantation: the impact of recipient and donor CMV serostatus on the incidence of CMV disease and CMV-related mortality. Bone Marrow Transplant. 2003;31:803-8.

106. Zhou W, Longmate J, Lacey SF, Palmer JM, Gallez-Hawkins G, Thao L, et al. Impact of donor CMV status on viral infection and reconstitution of multifunction CMV-specific $\mathrm{T}$ cells in $\mathrm{CMV}$ positive transplant recipients. Blood. 2009;113:6465-76.

107. Crocchiolo R, Castagna L, Furst S, Devillier R, Sarina B, Bramanti $\mathrm{S}$, et al. The patient's CMV serological status affects clinical outcome after T-cell replete haplo-HSCT and post-transplant cyclophosphamide. Bone Marrow Transplant. 2016;51:1134-6.

108. Cesaro S, Crocchiolo R, Tridello G, Knelange N, Van Lint MT, Koc Y, et al. Comparable survival using a CMV-matched or a mismatched donor for $\mathrm{CMV}+$ patients undergoing T-replete haplo-HSCT with PT-Cy for acute leukemia: a study of behalf of the infectious diseases and acute leukemia working parties of the EBMT. Bone Marrow Transplant. 2018;53:422-30.

109. Morishima Y, Sasazuki T, Inoko H, Juji T, Akaza T, Yamamoto $\mathrm{K}$, et al. The clinical significance of human leukocyte antigen (HLA) allele compatibility in patients receiving a marrow transplant from serologically HLA-A, HLA-B, and HLA-DR matched unrelated donors. Blood. 2002;99:4200-6.

110. Anasetti C, Beatty PG, Storb R, Martin PJ, Mori M, Sanders JE, et al. Effect of HLA incompatibility on graft-versus-host disease, relapse, and survival after marrow transplantation for patients with leukemia or lymphoma. Hum Immunol. 1990;29:79-91.

111. Kawase T, Morishima Y, Matsuo K, Kashiwase K, Inoko H, Saji $\mathrm{H}$, et al. High-risk HLA allele mismatch combinations responsible for severe acute graft-versus-host disease and implication for its molecular mechanism. Blood. 2007;110:2235-41.

112. Raiola AM, Risitano A, Sacchi N, Giannoni L, Signori A, Aquino $\mathrm{S}$, et al. Impact of HLA disparity in haploidentical bone marrow transplantation followed by high-dose cyclophosphamide. Biol Blood Marrow Transplant. 2018;24:119-26.

113. Lorentino F, Labopin M, Fleischhauer K, Ciceri F, Mueller CR, Ruggeri A, et al. The impact of HLA matching on outcomes of unmanipulated haploidentical HSCT is modulated by GVHD prophylaxis. Blood Adv. 2017;1:669-80.

114. Huo MR, Pei XY, Li D, Chang YJ, Xu LP, Zhang XH, et al. Impact of HLA allele mismatch at HLA-A, -B, -C, -DRB1, and -DQB1 on outcomes in haploidentical stem cell transplantation. Bone Marrow Transplant. 2018;53:600-8.

115. Foundation for the Accreditation of Cellular Therapy and Joint Accreditation Committee ISCT EBMT. International standards for hematopoietic cellular therapy product collection, processing and administration. 7th ed. Nebraska:FACT-JACIE, 2018. http://www.factweb.org/forms/store/ProductFormPublic/seventhedition-fact-jacie-internationalstandards-for-hematopoietic-cellulartherapy-product-collection-processing-and-administration-free-dow nload (viewed Nov 2018). 


\section{Affiliations}

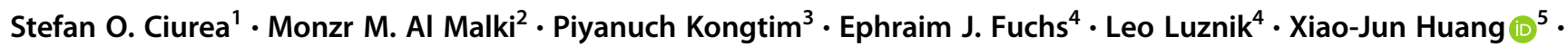
Fabio Ciceri ${ }^{6}$ - Franco Locatelli ${ }^{7}$. Franco Aversa ${ }^{8}$ - Luca Castagna ${ }^{9}$ - Andrea Bacigalupo ${ }^{10}$ - Massimo Martelli ${ }^{11}$. Didier Blaise $\mathbb{C}^{12}$. Patrick Ben Soussan ${ }^{13} \cdot$ Yolande Arnault $^{13} \cdot$ Rupert Handgretinger $^{14} \cdot$ Denis-Claude Roy $^{15}$. Paul V. O'Donnell ${ }^{16}$ - Asad Bashey ${ }^{17}$. Scott Solomon ${ }^{17} \cdot$ Rizwan Romee $^{18}$ - Jorge Gayoso ${ }^{19} \cdot$ Hillard M. Lazarus $^{20}$. Karen Ballen ${ }^{21} \cdot$ Bipin N. Savani ${ }^{22} \cdot$ Mohamad Mohty $^{23,24} \cdot$ Arnon Nagler $^{24,25}$

1 The University of Texas MD Anderson Cancer Center, Houston, TX, USA

2 Department of Hematology and HCT, City of Hope National Medical Center, Duarte, CA, USA

3 Department of Medicine, Thammasat University, Pathumthani, Thailand

4 Division of Hematologic Malignancies, Sidney Kimmel Comprehensive Cancer Center at Johns Hopkins, Baltimore, MD, USA

5 Institute of Hematology, Peking University People's Hospital, Beijing, China

6 Hematology and BMT Unit, San Raffaele Scientific Institute, Milan, Italy

7 Department of Pediatric Hematology and Oncology, IRCCS Ospedale Pediatrico Bambino Gesu, University La Sapienza, Rome, Italy

8 Hematology and BMT Unit, University of Parma, Parma, Italy

9 Hematology Department, Humanitas Clinical and Research Center, Milan, Italy

10 Instituto di Ematologia, Fondazione Policlinico Universitario Gemelli, IRCCS, Universita’ Cattolica del Sacro Cuore, Roma, Italy

11 University of Perugia, Perugia, Italy

12 Departement D’Hematologie, Programme de Transplantation et de
Therapie Cellulaire, Aix Marseille Univ, Inserm, CNRS, CRCM, Marseille, France

13 Departement de Psychologie Clinique, Institut Paoli Calmettes, Marseille, France

14 Department of Hematology and Oncology, Children's University Hospital, Tubingen, Germany

15 Blood and Marrow Transplantation Program, Hôpital Maisonneuve-Rosemont, Université de Montréal, Montreal, QC, Canada

16 Massachusetts General Hospital Cancer Center, Boston, MA, USA

17 BMT Program at Northside Hospital, Atlanta, GA, USA

18 Dana Farber Cancer Institute, Boston, MA, USA

19 Facultad de Medicina Universidad Complutense, HGU Gregorio Maranon, Madrid, Spain

20 Case Western Reserve University, Cleveland, OH, USA

21 University of Virginia Health System, Charlottesville, VA, USA

22 Vanderbilt University Medical Center, Nashville, TN, USA

23 Hopital Saint-Antoine, Paris, France

24 Acute Leukemia Working Party of the EBMT, Hopital SaintAntoine, Paris, France

25 Hematology Division, Chaim Sheba Medical Center, Tel Hashomer, Israel 